pursuers, and Stenersen (1972) describes how the artist used to assault complete strangers in response to the derogatory comments that he attributed to them.

The biographies are less clear about whether such symptoms can be totally attributed to Munch's undoubted misuse of alcohol, but whatever their cause the case of Edvard Munch helps to illustrate how great artistic achievement may result from both personal suffering and abnormal experience.

Heller, R. (1984) Munch: His Life and Work (pp. 195-198). London: John Murray.

Stenersen, R. (1972) E. Munch: Close-up of a Genius (p. 30). Oslo: Gyldendal Norsk Forlag.

Yarmouth Regional Hospital

PHILIP STOKes

Nova Scotia

Canada

\section{Lack of care in Rwanda}

SIR: Rene Stockman's description (BJP, August $1994,165,145-148$ ) of psychiatric services in Rwanda is now tragically dated. I have recently returned from a mission to $R$ wanda on behalf of Physicians for Human Rights (UK). Many people will have seen the $\mathrm{BBC}$ report of our second visit to the hospital at Ndera near Kigali. We found only 22 surviving patients, most of whom appeared to be suffering from a recrudescence of psychotic symptoms. The last member of staff had left four days before our visit and the patients had received no medication for over a week.

Evidence of the ferocity of the attack on the hospital abounded. Grenade damage to floors and roofs was extensive and automatic fire had raked the building. Unburied human remains littered the ground to the rear of the hospital. Among the most shocking findings was the condition of three allegedly violent, psychotic patients who had been incarcerated by the refugees who had taken over most of the building. Confined to tiny cells, their chances of survival seemed slim.

The scale of psychological disturbance among the survivors of the recent genocide compounds the tragedy. We carried out a survey of psychiatric morbidity, in the towns of Rwamagana and Gahini in east central Rwanda. This area was chosen as being one of the most settled in the country. The massacres only occurred for two to three weeks before the RPF over-ran former government forces.

The instrument used was the 20-question neurotic subscale of the WHO Self Report Questionnaire (Hardinge et al, 1980). Preliminary scrutiny of the responses suggests a 'caseness' rate of over $90 \%$.
We deliberately excluded the psychotic subscale, since the first question in particular ("Do you feel that people are trying to harm you?") seemed so wholly inappropriate to the circumstances. Indeed the scale of the disaster that has befallen Rwanda almost defies quantification.

It is to be hoped that in the rush to meet the immediate and pressing physical needs of the people of $\mathrm{Rwanda}$, some $70 \%$ of whom are either refugees or internally displaced, their equally urgent psychological needs are not ignored. In particular, appropriate models for the treatment of severely traumatised children, and training in their application, will be needed if the cycle of violence which has beset this country for so long is to be broken.
Hardinge, T. W., De Arango, M. V., Baltazar, J., et al (1980) Mental disorders in primary health care: a study of their frequency and diagnosis in four developing countries. Psycho- logical Medicine, 10, 231-241.

ANDRew Carney

Harperbury Hospital

Harper Lane

Radlett, Herts

\section{Cognitive therapy in panic disorder}

SIR: The study by Clark et al (BJP, June 1994, 164, 759-769) poses problems concerning its claims for cognitive therapy in panic disorder.

1. The patients had relatively mild panic disorder. Apart from having no marked agoraphobia, they had only about 2.7 panics a week, compared to over four a week in larger multinational studies (Cross-National Study, 1992; Marks et al, 1993). The study gives no work or social disability measure.

The authors write of "the need for a psychological treatment for the less phobic panic disorder patients whose attacks were thought unlikely to be completely eliminated by situational exposure alone". Exposure is such a psychological treatment, and eliminated $96 \%$ of panics in severe panicl agoraphobia (see below). As it works best in less severe cases (Basoglu et al, 1994a), exposure would have been suitable for the $81 \%$ of Clark et al s cases who had agoraphobic avoidance and for some of the remaining $19 \%$ who had situational panics.

2. The study's 'control' group was simply on a waiting list, which did not control for the nonspecific factor of attendance and rating over 10 sessions-omission of such a placebo control is crucial. In the studies cited above placebo had a major anti-panic effect (but not an anti-phobia effect). Six months post-entry, although panic 